University of Wollongong

Research Online

Faculty of Engineering - Papers (Archive)

Faculty of Engineering and Information

Sciences

$1-1-2005$

\title{
Stakeholder communications for successful water reuse operations
}

Stuart J. Khan

University of Wollongong

L. E Gerrard

Bluebird Communication, NSW

Follow this and additional works at: https://ro.uow.edu.au/engpapers

Part of the Engineering Commons

https://ro.uow.edu.au/engpapers/3200

\section{Recommended Citation}

Khan, Stuart J. and Gerrard, L. E: Stakeholder communications for successful water reuse operations 2005, 355-367.

https://ro.uow.edu.au/engpapers/3200

Research Online is the open access institutional repository for the University of Wollongong. For further information contact the UOW Library: research-pubs@uow.edu.au 


\title{
Stakeholder Communications for Successful Water Reuse Operations
}

\author{
S.J. Khan ${ }^{\mathrm{a}^{*}}$ and L.E. Gerrard \\ ${ }^{a}$ Environmental Engineering. The University of Wollongong, NSW, 2522, Australia. \\ Tel: $+61242213385 . \mathrm{Fax}+61242214738$. E-mail: skhan aumow.edu.au \\ ${ }^{b}$ Bluebird Communication. Springwood. NSW. Australia. Tel: +61247252592 , Fax +61247252168. \\ E-mail: lis.gerrard(âbigpond.com \\ *Corresponding author.
}

\begin{abstract}
A well-organised, comprehensive communications program with stakeholders is essential to any modern water reuse project. To maximise trust between water reuse organisations and stakeholders, the communication process needs to begin long before project plans are drawn up and contimue throughout the life of any project. It must begin with the decision to seriously consider the development of a scheme and remain highly visible throughout all of its stages, including planning, construction, implementation and operation. The conmunications program must also embrace any extensions of the project.

This paper relates to a study that was undertaken in the preliminary preparation of a manual of best practice for water recycling operations. The purpose of the study was to provide an understanding of major communication issues to be addressed and successful means of addressing them. Ten key messages to stakeholders were established during the process and are presented here.
\end{abstract}

Keywords: Water recycling, water reclamation, key messages.

\section{Introduction}

Communication is a complex process that takes place between two or more parties, whereby information is delivered, received. interpreted and responded to. To be successful, water reuse organisations must communicate effectively with their stakeholders. Stakeholders are organisations and individuals with an interest in a particular project. They include public agencies at all levels, landowners, industry and commerce, special interest groups. customers, potential customers, community leaders and the community in general.

A growing number of water reuse projects around the world have failed and been abandoned as a direct result of a lack of community confidence in the projects. They include water reuse schemes in Europe, Australia and the USA. In each case, community misgivings could be attributed, in part, to inadequate communication between water reuse organisations and their stakeholders. In some cases. communities suspected that planning was being undertaken in secret and that their concerns were being ignored. In others, water reuse organisations failed to adequately promote the benefits of their operations. Even more detrimental was the failure of reuse organisations to allay stakeholder fears about possible health and environmental risks associated with water reuse.

For many important decisions, debate among stakeholders is to be expected. Furthermore, it should be welcomed and encouraged since it can very often lead to improved or more mutually satisfactory outcomes. However, for debate to be constructive, effective communication is paramount.

The nature and extent of a successful communications program will depend mainly on the complexity of information to be imparted and an assessment of any 
factors that may have the potential to damage the relationship between a water reuse organisation and its stakeholders. Effective communication is an ongoing process. It begins with the decision to consider a water reuse scheme and continues throughout the life of any scheme.

\section{Stakeholder views of water reuse and water reuse organisations}

In developing a communications program. it is essential that the knowledge. attitudes and perceptions of stakeholders. as they relate to the full strata of physical and emotional issues relating to water reuse. be understood. acknowledged and addressed.

Lay people generally respond to a broader range of issues and may base their judgements on quite different values to those of practitioners and experts. While the views of lay people may change as their knowledge and understanding of a project increase. it should not be assumed that they will eventually share all the views of the practitioners or experts. Nor should it be assumed that any discrepancy in outcome is the result of misunderstanding or unsound reasoning.

Understanding stakeholder views towards individual schemes may require considerable local research. A useful starting point will be to consider the findings of previous studies and their potential to be applied to current and future operations.

\subsection{Communitv view's of water reuse}

Different communities and different stakeholders within communities will have varying views of any contentious initiative, including water reuse. For many communities planning for the future, the role of water reuse, whether it be for potable or non-potable supply, is untested. Hence, issues that may influence community response to water reuse are likely to include those associated with:

- public health

- environmental health

- economy and finance

- available technology

- emotional factors

Community views of water reuse have been a topic of interest to social scientists since the early 1970s. Much of the research conducted during the 1970s and 1980s in the USA has been summarised by Bruvold [1]. These studies indicated acceptance of more than 90 per cent for the reuse of wastewater to irrigate recreational parks, golf courses, lawns, gardens and hay pastures. Substantial acceptance (80 to 90 per cent) was often reported for the irrigation of dairy pastures and edible crops including orchard, vineyard and vegetable crops. Uses involving closer human contact with recycled water but minimal likelihood of ingestion. such as for household toilet flushing and clothes washing, had more variable acceptances of from 70 per cent to more than 90 per cent. Uses involving close human contact and reasonable possibility of unintentional ingestion, such as for swimming and bathing at home, had reported acceptances of 60 to 75 per cent. The lowest levels of acceptance (30 to 60 per cent) were consistently reported for uses where direct human ingestion was likely or inevitable such as for drinking and cooking.

It is clear from these trends that the likely degree of close human contact is important in determining community acceptance of water reuse schemes. However, most of the studies involved theoretical proposals and 'in principal' support. Where actual or potentially imminent water recycling projects are involved, factors such as 
environmental and conservation matters as well as water treatment costs and water distribution costs tend to be more important [1].

Water treatment technology has undergone considerable development and improvement since the 1980s. However, studies from the USA [2] and Australia [3] since then, indicate that community support for many forms of water reuse has either remained largely unchanged or decreased over the years. As such there appears to be no strong correlation between the quality of reuse water and community acceptance of its use for specific applications.

To fully understand community attitudes to water reuse, it is necessary to consider instinctive and emotional responses that people have to human excrement and sewage issues. It has been illustrated that many people trust their own impressions of water quality (often based on cloudiness of the water) more than they trust medical and scientific evidence [4]. Cognitive factors such as the Law of Contagion and the Law of Similarity may explain many of the less rational perceptions that people may have about water reuse [5]. The Law of Contagion suggests that once water has been in contact with contaminants. it can be psychologically very difficult for people to accept that it has been purified. The Law of Similarity suggests that the 'appearance' of a substance's condition or status is psychologically linked to perceptions of reality. Combined. these factors can create mental barriers to the acceptance of reuse water as a source of pure water.

A review of studies undertaken up to early 2000 identified ten factors as contributing to the degree of community acceptance of water reuse options [4]. The review suggests that community acceptance of water reuse is higher when:

- degree of human contact is minimal

- protection of public health is clear

- protection of the enviromment is a clear benefit of the reuse

- promotion of water conservation is a clear benefit of reuse

- cost of treatment and distribution technologies and systems is reasonable

- perception of wastewater as the source of reuse water is minimal

- awareness of water supply problems in the community is high

- role of water reuse in the overall water supply scheme is clear

- perception of the quality of reuse water is high

- confidence in local management of public utilities and technologies is high

Not surprisingly, the water reuse applications that have consistently least enjoyed community support have been those that involve recycling treated sewage to drinking water supplies. In the USA, acceptance of potable reuse applications was measured at 48 per cent in 1971 , but this appears to have fallen significantly to 26 per cent (California) by 1979 and 29 per cent (Denver) in 1985 [1]. By 2002 support in the USA for direct potable reuse was reported at only 18 per cent while support for indirect potable reuse was at 40 per cent. The difference in support for the two approaches highlights important differences in perceptions of them [2]. Furthermore, the degree of support reported for potable reuse schemes has depended very much on the survey questions. For example, questions about potable water reuse policy consistently score a more positive response than those about intentions to drink the recycled water [3].

In some cases, community acceptance of water reuse may be significantly influenced by regional circumstance. In particular, severe shortage of fresh water supplies is likely to encourage communities to look for alternative supplies. Windhoek in Namibia and Singapore provide two extreme examples.

Windhoek suffers from a combination of very low rainfall, high evaporation and limited catchment area. All surface waters within $500 \mathrm{~km}$ of the city are fully utilised 
and groundwater sources are similarly exploited. Demand management policies have not been sufficient to curb the imbalance between water demand and fresh water supply. The City of Windhoek now recycles water from sewage treatment plants directly to drinking water plants to supply about one third of its potable requirements. This recycling practice is well publicised and recent upgrades of the treatiment plant have been launched by the President of the Republic of Namibia. with full media coverage. Comprehensive studies of community attitudes to potable reuse in Windhoek have not been done. However, anecdotal evidence suggests that the community takes considerable pride in their city's ability to overcome environmental adversity and in its role as a world pioneer of direct potable reuse [6]. Nonetheless, it is difficult to extrapolate observations from Windhoek to the far removed cultural and public health settings of highly industrialised countries.

There appears to be a high level of stakeholder support for direct potable reuse in Singapore also. The combination of need and belief in the government's ability to effectively address that need is largely credited for the support [7]. Singapore is a small island republic with extremely limited natural fresh water supplies. For many decades, it has relied heavily on its neighbour. Malaysia. for much of its potable water. Such heavy reliance on a foreign country for a resource as crucial as water sits uncomfortably with many Singaporeans. The prospect of secure, self-sufficient water supplies, combined with the respect afforded to political leadership and government institutions in Singapore, is likely to have been a significant factor in generating support for potable reuse. However, regardless of these regional circumstances, success in building and maintaining community support in Singapore may be partially attributed to persistent stakeholder engagement as well as innovative and extensive community information and education programs [7].

It is apparent that people's acceptance of water reuse schemes varies over time and from locality to locality. Therefore. ongoing studies at the local level will be necessary to keep pace with community sentiment in each instance.

It is clear that schemes involving potable reuse. and particularly direct potable reuse, are likely to be the least acceptable option for many communities. However, there is evidence that a high level of awareness of need for water reuse combined with other advantageous circumstances will encourage some communities to become highly supportive, even proud; of direct potable water reuse operations.

\subsection{Trust and credibility}

Success of water reuse projects will largely depend on the credibility of the supplier of information. The credibility of the water reuse organisation and its senior managers is as important to the success of the project as the quality of the project itself. It was recently found that the degree of trust that an individual had for a water authority was proportionate to the individual's level of confidence that a planned reticulated water reuse supply would not pose unacceptable risks to their health or garden [8].

The credibility of a water reuse organisation will be judged on a number of factors. which may include perceptions of the organisation's:

- commitment to the welfare of the stakeholders

- performance record based on previous initiatives

- knowledge of the issues, as demonstrated by spokespersons

- impartiality regarding the subject matter

Recent observations suggest that wastewater utilities may be suffering from a general decline in community trust and confidence in civic agencies and officials [4]. Surveys indicate that water and sewerage authorities typically command the least degree 
of community trust. The medical profession commands the greatest degree of community trust. followed by public health authorities, reputable research institutions, environmental protection agencies and non-government environmental groups [3].

In instances where the community associates a high level of risk with a water reuse project. trust has shown to be maximised when the following conditions are met [4:9]:

- Dialog is sustained

- The community has independent sources of information, not linked to the sponsoring agency

- The community can ask questions

- The community is involved early

- Information is available to everyone

- Behaviour is non coercive. It is considered a reasoned and fair way to make a decision

- Everyone's opinion matters, and there is a willingness to listen to all views and expand the discussion if necessary

- Citizens have some level of control in the process (such as by contributing to the agenda or ground rules)

\subsection{Community risk perception}

Community assessment of risks posed by various activities has been reported in many cases as being different from risk assessment by experts or govermment agencies [10]. Since the early 1980s, there have been many approaches taken in identifying the determinants of public risk perception. Many of the studies have indicated that the layperson's assessment of risk is often subjective rather than based on objective risk indicators. Many have also found that large numbers of people judge the levels of risk associated with many human activities or technologies as being unacceptably high [10].

Research indicates that communities are generally concerned about such issues as long-term effects of risk-based activities, equity and fairness issues. lack of personal control and the pace of teclmological intrusion into their cultural environment [11].

Recent survey results suggest that a majority of people regard the concept of water reuse as posing an acceptable risk [7]. An important finding of this study was that overall communities are more accepting of risk associated with water supply than it is with other commonly encountered risks.

While water reuse generates a strong emotional response in people, it does not cause them to conclude that the practice poses a high risk of death [7]. Instead. many people have enough knowledge of water reuse to critically assess their emotional response. This indicates that community perception of risk associated with water recycling is not necessarily dominated by emotional factors.

\subsection{Encouraging opportunities}

There is reason for water reuse organisations to be optimistic and enthusiastic in their communication efforts. Despite the challenges, a review of recent studies has revealed highly encouraging data about community perceptions and attitudes towards water reuse, at least in the USA [4]. It is anticipated that many of the findings will also apply to other countries. The findings highlight opportunities for effective communication between water reuse organisations and their stakeholders. They include the following.

- The community is interested in being meaningfully involved in water reuse decisions. 
- The community is interested in finding ways to ensure independent and secure water supplies for their communities.

- While the community is not well versed in the water cycle. they are generally aware that there are water supply problems in many parts of the country (the USA).

- The community believes that some form of potable reuse is inevitable, given growth and water supply constraints.

- Information sharing, educational activities and opportunities for reflection upon the concepts of water reuse can increase support.

\section{How water reuse organisations communicate with stakeholders}

Communication can take many forms with many different ratios of input to the process by the separate parties. The degree and nature of communication will be influenced by a number of factors. The greater the degree of real or perceived risk associated with a project. the greater the levels of communication. stakeholder input and negotiation that will be required to achieve a successful outcome.

\subsection{Defining and identifying successful communication}

The degree to which a communication effort has been successful must be judged according to its aims. Specific aims may vary depending on particular circumstances. A very basic aim may be to inform stakeholders about water reuse. The aim of a more complex communication strategy may be to provide stakeholders with sufficient knowledge to enable constructive engagement in a public discussion or to effectively manage conflict. Some aims of communication strategies may be more outcomesfocused such as to encourage stakeholders to become more supportive of a reuse proposal or even to accept a proposal whether they support it or not. Some organisations may communicate with stakeholders with the simple aim of meeting legal requirements and avoiding litigation.

In most circumstances, a successful communications program will contain strategies that allow stakeholders to study the evidence and draw their own conclusions about water reuse. They will be able to see both the decision-making process and the decisions themselves as being transparent and fair. A successful communications program will also engage stakeholders to share responsibility for solving the water supply or wastewater disposal problem.

\subsection{Early and continuous communication}

The timing of communication activities can be of equal importance to their substance. Community confidence and trust can only be built over time. Therefore. rollout of a successful communications program will ideally begin as a component of the broader resource planning effort when the potential to develop a reuse project is being considered. Taking this approach will help develop community confidence and trust within what is likely to be a neutral environment, outside the context of an imminent, controversial plan.

The supply of information to stakeholders will need to coincide with major decisions made by water reuse organisations and other relevant bodies. It will also need to coincide with the outcomes of other communication processes. It is important that stakeholders first hear of major developments, be they positive or negative, from the project managers. Delays in passing on information may give rise to rumours, increase levels of concern and cause stakeholders to question the organisation's motives and 
intentions. Such reactions will greatly undermine stakeholder trust and be detrimental to the project.

\subsection{Listening and seeking clarification}

With the vast majority of water reuse projects, the "we tell you what you should think and know' approach will at best be ineffectual and at worst highly counterproductive. It is therefore important for communication to be established as a two-way flow between the reuse organisation and all stakeholders as soon as the decision to seriously consider a project has been made. With that decision comes the beginning of a learning process that will continue throughout the life of the project for everyone involved.

Two crucial characteristics of effective communication are listening and seeking clarification. By providing readily accessible listening and feedback opportunities, water reuse organisations can monitor the concerns and opinions of their stakeholders. Surveys, internet and telephone hotlines provide effective avenues for such communication strategies. Other approaches such as holding informal open-house events. public forums and focus group meetings increase the dimension of opportunities to listen to stakeholders.

\subsection{Risk communication}

An essential component of any communications program is risk communication. Historically, the major goals of risk communication have been to align the community's perception of risk with that of the risk experts and to reduce the fear and community resistance of risk-related technology [10]. However, for projects that are politically controversial, the current notion is that risk communication should focus on more basic matters. These include a society's values concerning procedural fairness. the way in which society makes judgments and reaches decisions, and the fairness with which risks and benefits are distributed across different sectors of the community [10]. Fundamental to successful risk communication is the willingness of all stakeholder groups to respect the views of others and for all concerns to be included in the decision making process [11].

The United States Environment Protection Agency promotes seven steps to successful risk communication [12]:

- Accept and involve the community as a legitimate partner.

- Plan carefully and evaluate your efforts.

- Listen to the community's specific concerns.

- Be honest, frank, and open.

- Coordinate and collaborate with other credible sources.

- Meet the needs of the media.

- Speak clearly and with compassion.

\section{Identifying key messages to stakeholders}

By engaging stakeholders in any decision-making process, a water reuse organisation is asking them to make informed judgments. Hence it is essential that an education program will need to form part of the overall communications program to enable such judgements to be made. Communication managers will have to determine the extent to which stakeholders need to assimilate new information and become familiar with the various abstract and technical concepts before being able to make those informed judgments. 
Water reuse is a relatively new concept for many communities. Therefore its value must be presented in simple, but compelling terms. Positive key messages about water reuse will reinforce community acknowledgement of its benefits for people and the environment. Many of the key messages are universal. However as previously demonstrated by Windhoek City and Singapore. individual communities are likely to base their acceptance of water reuse and rate its advantages largely according to local considerations such as climate, geography and culture.

For comununities that are subject to severe drought and unreliable water supplies, the emphasis will be on promoting water reuse as a source of alternative supply. The first step of the communications program will be to let stakeholders know that there is a serious. long-term water shortage problem that is in urgent need of being addressed. Stakeholders must be assured that the problem will be addressed. reasonably and sympathetically, by the appropriate organisation. There needs to be a guarantee that the problem will be solved in collaboration with stakeholders who will benefit from the solution.

In other instances. the search for viable alternatives to wastewater discharge will be the main driver of a water reuse program. A vulnerable marine environment or riverine system that has been significantly impacted by wastewater disposal provides a powerful argument for water reuse. Prominent stakeholders such as a local surfing community and some sectors of the tourism industry are likely to find in favour of reuse as an alternative to disposal and prove to be powerful activists for the proposal.

Water reuse has many forms; some involve recycling treated sewage to the municipal drinking water supply and some do not. It is important for the communications program to remain focused and pertinent. For example, if the scheme being proposed is for industrial reuse only. communication strategies that address such issues as perceived health risks associated with drinking recycled water are irrelevant and likely to be counterproductive.

A highly proactive communications program helps a water reuse organisation establish and maintain credibility by setting the agenda and an open discussion process. It places the organisation in a strong position to acknowledge and address emerging issues up front rather than having to defend its position when the issues are used as ammunition against it.

The following sections discuss key messages for the promotion of water reuse activities. The messages are presented in general terms so that they may be widely applicable. However in many cases, important local issues will prevail and key messages may need to be tailored to specific groups of stakeholders.

\subsection{Water reuse organisations earn their good reputation}

Although it is possible to raise community awareness of water treatment technologies. it is not realistic to expect a layperson to fully understand the intricate details of treatment processes and risk. At some point, the community will need to place its trust in the water reuse organisation to protect public health and the environment. No amount of reassurance about levels of treatment and monitoring can overcome a lack of trust in the organisation itself.

It is important for water reuse organisations to communicate good reasons why it is worthy of a community's trust. Since trust must be built up over time, a good reputation is the strongest argument for on-going trust. The water reuse organisation should seek to remind the community of past circumstances, or an on-going history, where trust placed in it has proved to be warranted. 
Worthiness of trust is a message that is most effectively communicated when actions accompany the words. Water reuse organisations must indeed earn their good reputation and the confidence of its stakeholders. Their ability to do this will be greatly enhanced by dealing with issues as they arise and communicating with stakeholders early and often. Trust is generated with transparency and accountability.

Trust can be enhanced with public documents and websites that are easy to locate and easy to understand. Trust may be further promoted by collaborative research and fact finding initiatives. with reputable researchers in universities and research organisations. Such projects can generate stakeholder confidence that decisions are made based on robust scientific, socio-economic and financial knowledge.

\subsection{The reuse project has a critical need and clear purpose}

The onus will be on the water reuse organisation to make an effective case for the development of a project. This should be communicated in terms of the project's role in the overall water management strategy in the service area.

During prolonged periods of drought. communities can become acutely 'water aware' and inclined to support innovative, non-conventional water management strategies. However. collective memory can be short. Once droughts break and the impetus is lost, water reuse organisations may find the task of convincing stakeholders of the need for water reuse to be considerably more difficult.

Raising and maintaining community awareness of the importance of the underlying issues and the role that water reuse has in addressing those issues should remain a high communication priority.

\section{t.3. Reuse water is safe for its intended uses}

Safety should be promoted as the utmost concern of the water reuse organisation. It may be appropriate to highlight an excellent or unblemished safety record for water reuse in the particular region or for the planned applications. Performance histories. including maintenance and accident records, are important factors that will influence community judgement of reuse water as a safe and reliable product.

The conmunity should be informed that water reuse schemes operate according to strict public health and safety guidelines that have, in many cases, been approved or endorsed by health services. It is also important to emphasise that the health-related aspects of an operation are closely regulated and overseen by appropriate authorities. Furthermore, it should be noted that the relevant health services are extremely cautious and rigorous in setting water quality standards and criteria for reuse water and for water reuse systems.

Emphasises should be placed on the high level of treatment that reuse water undergoes to remove pathogens and on the degree of testing to assure that water quality standards are met. However, it is important not to overwhelm stakeholders with excessive amounts of technical information. The fundamental message should be that the water reuse technology is safe, reliable and effective. An analysis of the reuse water will demonstrate its suitability for targeted uses.

It is often helpful to point out that the process followed in treating water for reuse closely mimics the way nature cleans water, but the engineered process is much faster and more controlled. The technology for producing water suitable for reuse has dramatically improved over time, ensuring that reuse water remains a safe and valuable resource. If further information is deemed appropriate, jargon-free descriptions of water treatment processes should be offered. As an example, a Californian water utility explains water treatment technologies to its customers with descriptions such as the 
following. 'Secondary treatment uses 'good' bacteria or microbes like those found in nature to decompose the organic materials in the wastewater and to destroy harmful organisms. Air is pumped into aeration tanks to keep these microbes alive to do their essential work' [13].

However. water reuse organisations should be careful not to over-sell the safety of reuse water for fear of dispelling appropriate caution. For example. in many instances reuse water supplies are not intended for various uses such as drinking or food preparation. Over-stating the safety or quality of the water may lead people to incorrectly assume that such uses are acceptable nonetheless. Use of reuse water should be clearly described and continuously communicated.

\section{4.t. Water reuse helps conseme drinking water supplies}

Water is in short supply in many parts of the world. Increasing populations. coupled with the occurrence of drought, makes future water supply reliability a major concern. Water conservation efforts help but are often not enough to offset increased demand.

In many instances, the role of a water reuse scheme in conserving drinking water supplies may not be obvious to the community. For example, it may be necessary to point out that every industrial process that reuses water instead of sourcing fresh water from a potable supply stretches the local fresh water supply by the equivalent amount and helps 'drought proof' the community.

A further means by which water reuse can help conserve drinking water supplies is by providing a barrier against the intrusion of salt water into drinking water aquifers.

\subsection{Water reuse is beneficial for the environment}

The reuse of water benefits the environment by reducing the amount of treated wastewater discharged to rivers, bays and oceans. In some cases, water may be reused to augment flow rates of natural water bodies. This practice is distinguishable from sewage discharge by the higher level of water treatment and more controlled release programs. By reducing pressure on fresh water supplies, water reuse also helps maintain adequate freshwater flows within the rivers and streams that fish and wildlife depend upon.

Reusing water for irrigation purposes may have additional environmental advantages. Irrigation schemes based on the reuse of water can be the means of recycling important soil nutrients such as phosphorous and nitrogen back to farmlands. Such activity reduces the discharge and impact of these nutrients on aquatic environments, while reducing the need to apply synthetic fertilisers to farmland.

\section{t.6. Water reuse may have significant positive economic impacts}

Economic implications of a water reuse scheme are important to stakeholders on two levels. First, stakeholders will want to be satisfied that public funds are to be spent responsibly and reap optimum returns. Second, many stakeholders will have a more personal interest in the economics of the scheme.

As a reliable source of water for industry or agriculture, water reuse schemes may have a substantial positive impact on a local economy. Such advantages are likely to be enthusiastically embraced by the community and should be broadly promoted. Water reuse can similarly protect public and private investment in parks and landscaping enterprises since it is available in times of drought.

Where reuse water is to be reticulated as an alternative supply to households, personal economic incentives may be attractive. In most current 'dual-reticulated' 
schemes, reuse water is sold to households at a lower price than potable water. Consequently, its use for approved applications may substantially reduce the overall water expenses for many households.

Additionally, water reuse may be a less expensive option for the community than alternative options such as desalination or the construction of large-scale ocean outfalls. However, water reuse organisations should tread carefully and avoid any suggestion that the principal advantage of a water reuse scheme is merely that it is the cheapest option.

\subsection{Water reuse is preferable to alternative strategies}

Individual scientists, environmentalists and others often have conflicting opinions about the various alternative water management strategies. Competing strategies can include seawater desalination. enhanced groundwater extraction. inter-valley transfer of surface waters and various disposal options. The conflicting views can lead to confusion amongst stakeholders about the merits of the respective strategies.

Unless there are communications programs in place that promote the reasons for a preferred water management strategy, the argument has the potential to divide a community. The most favourable approach is to communicate the advantages and disadvantages of all the options and demonstrate how the preferred option is the most suitable.

In many cases, it can be useful to remind the community that there are two major water management issues to be addressed. One is to overcome impending shortages of supply. The other is to limit the environmental implications of continuing to dump everincreasing volumes of treated sewage into the world's rivers and oceans. Only water reuse can meet these challenges simultaneously.

There is a growing trend for certain sectors of some coastal communities to vigorously promote seawater desalination as a safe 'unlimited' supply option. However, such promotion rarely takes account of the greater energy requirements for desalination schemes compared to the energy requirements for water recycling schemes. In such instances, the onus will be on the water reuse organisation to inform the community of the facts by providing balanced information about the options.

\subsection{There are specific intended, approved or appropriate uses of reuse water}

The intended applications of a reuse water supply will significantly influence the degree of community acceptance of a scheme. Communicating the details will allow the community to judge the likely degree of contact it will have with the reuse supply. It may also help to dispel any misinformation that may have been circulating within the community. Clear messages to the community regarding approved applications of the recycled water will also be crucial in preventing misuse.

A number of countries have guidelines that make it mandatory for a water reuse supply's infrastructure to be clearly distinguishable from other water systems to avoid mixing of supplies. Where reuse water is to be re-reticulated back to households, standard practice requires separate plumbing systems for drinking water and reuse water. The communications program should include strategies that enable the community to become proficient at being able to distinguish between the two systems. This is to help avoid situations of increased risk as well as the potential public-relations disasters that may result from cross-connections between the systems.

\subsection{Water reuse is successfully practised in many other places}

A sceptical community may be reassured if informed of the enduring success that a growing number of other communities are having with water recycling projects 
similar to that being proposed. NEWater in Singapore uses this strategy most effectively. Visitors to the NEWater recycling plant and visitor centre are encouraged to watch persuasive video presentations of Californian residents proudly extolling the virtues of the Californian Water 21 water reuse scheme.

No community wants to feel like a 'guinea pig' for a new idea. Therefore. understanding that other communities, in wealthy countries, practise water reuse as a matter of some choice can be a powerful endorsement.

\subsection{All water is reused}

Many towns and cities throughout the world are already practising indirect potable reuse, though it is not always well recognised. Major waterways in Europe, the USA and Asia are used for both wastewater discharge and sources of freshwater supplies. Even groundwaters may substantially comprise recently percolated surface waters that have been subjected to influxes of disposed wastewaters.

Some 'big picture' concepts can be helpful to people when considering the implications of water reuse schemes. For example, the earth has approximately the same amount of water as it did a million years ago. The amount of water remains constant as it goes through the hydrologic cycle of precipitation in the form of rain or snow, runoff and evaporation. A proportion of every glass of water we drink has already been through insects, plants and animals - including people. Understanding that current technology primarily represents an acceleration of natural recycling processes is vital to the acceptance of water reuse schemes.

\section{Conclusions}

Effective two-directional communication enables water reuse organisations to develop an understanding of their stakeholders. The profile. encompassing stakeholders views. concerns and expectations will inform a water reuse organisation's subsequent decisions. It will provide project managers with a clearer picture of the communication strategies required for successful outcomes. It will also help them determine how and where to best invest a communication budget for the greatest return.

A successful communications program can, over time, establish an informed community that is comfortable with the concept of water reuse. knowledgeable about the issues involved and supportive of the program to be implemented.

Communication builds trust between organisations and stakeholders. The level of trust in an organisation has a major influence on the level of community support for proposed water reuse projects.

Ten key communication messages have been identified in this study. They encompass a range of social, environmental and economic issues of interest to stakeholders. The principal goals of the key messages are to promote the benefits of water reuse schemes and to allay community fears.

Most importantly, managers should never become complaisant. Over time communities alter. People move into an area or leave it. The community's size. demographics, and attitudes towards water reuse may all be subject to change. Accordingly, the communication process should be embraced as an on-going activity that benefits stakeholders as well as water reuse organisations. 


\section{Acknowledgement}

This project is proudly supported by the International Science Linkages programme established under the Australian Government's innovation statement Backing Australia's Ability'. OzAquarec: Integrated Concepts for Reuse of Upgraded Wastewater in Australia (CG030025) forms part of the European Union 5th Framework Project AQUAREC: Integrated Concepts for Reuse of Upgraded Wastewater (EVK1CT-2002-00130). The authors thank Dr. Troy Hartley for his insightful comments.

\section{References}

[1] Bravold. W. H. (1988) Public opinion on water reuse options. J. Water Poll. Control Fed., 60(1), 45-49.

[2] Hall, W. L. and Rubin. A. R. (2002) Reclaimed water: A public perception. In: WEFTEC 2002: 75th Annual Conference and Exposition Chicago, Illinois. USA.

[3] Marks. J. (2004) Advancing community acceptance of reclaimed water. Water, $31(5), 46-51$.

[4] Hartley, T. W. (2003) Water Reuse: Understanding Public Perception and Participation, Water Environment Research Foundation, Washington DC.

[5] Haddad. B. M. (2004) Research Needs Assessment Workshop: Human Reactions to Water Reuse, WateReuse Foundation. Alexandria. VA. USA.

[6] du Pisani, P. L. (2005) Case study on direct reclamation of potable water at Windhoek's Goreangab Reclamation Plant. In: Integrated Concepts in Water Recycling Wollongong, NSW, Australia.

[7] Macpherson, L. and Law. I. (2003) Winning minds to water reuse: The road to NEWater. In: 19th Annual WateReuse Symposium: Water Reuse -A Resource Without Boarders WateReuse Association, San Antonio, Texas, USA.

[8] Hurlimann. A. and McKay. J. (2004) Attitudes to reclaimed water for domestic use: Part 2. Trust. Water, 31(5), 40-45.

[9] Renn, O., Webler, T. and Wiedermann. P. (1995) Faimess and Competence in Citizen Participation: Evaluating Models for Environmental Discourse. Kluwer Academic Publishers, Boston.

[10] Gurabardhi, Z., Gutteling, J. M. and Kuttschreuter, M. (2004) The development of risk communication. Science Communication, 25(4), 323-349.

[11] Renn, O. (2004) Perception of risks. Toxicology Letters, 149(1-3), 405-413.

[12] USEPA Office of Emergency and Remedial Response (2002) Superfund Community Involvement Handbook., Washington. DC.

[13] East Bay Municipal Utility District (2004) Irrigation Customer Guidelines for Using Recycled Water, Oakland, California, USA. 